\title{
Audit on knowledge and practice of obtaining informed consent for invasive procedures among intern medical officers
}

\author{
Nimali Lochanie ${ }^{1^{*}}$, Nuwan Ranawaka ${ }^{2}$, Vasanti Pinto ${ }^{3}$ \\ Registrar in Anaesthesiology ${ }^{1}$, Registrar in Medicine ${ }^{2}$, National Hospital of Sri Lanka, Senior Lecturer in \\ Anaesthesiology ${ }^{3}$, Department of Anaesthesiology, University of Peradeniya, Sri Lanka.
}

*Corresponding author: lochanie1981@yahoo.co.uk

\begin{abstract}
Background
Every medical practitioner has ethical, professional and legal responsibilities to respect patients' autonomy with regard to informed consent.
\end{abstract}

\begin{abstract}
Methodology
Intern Medical Officers (IMO) in the first 6 months of internship at the National Hospital of Sri Lanka (NHSL) were given a self-administered questionnaire designed in 2 parts to assess the practical application and theoretical knowledge of obtaining informed consent. Data was analyzed statistically using SPSS 20.
\end{abstract}

\begin{abstract}
Results
$47.61 \%$ of IMO's had given information verbally. $100 \%, 97.61 \%$ and $41.86 \%$ had informed the nature, risks and alternatives respectively. $21.43 \%$ had discussed risk versus benefit. $78.57 \%$ had informed the consequences if left untreated. $83.33 \%$ had given the opportunity to clarify doubts. $51.51 \%$ of doctors who had not given all details said they did not have adequate time.

$73.80 \%$ had obtained consent for elective procedures a day prior. $11.9 \%$ had used a pre-prepared consent form. $88.09 \%$ had documented. There was a statistically significant tendency of not documenting alternatives $(\mathrm{p}<0.01)$, risk versus benefit $(\mathrm{p}<0.01)$ and consequences if left untreated ( $\mathrm{p}$ 0.032) despite providing information on them.
\end{abstract}

$95.23 \%, 85.71 \%$ and $47.61 \%$ of IMO's had correctly answered questions on capacity to consent from competent patients, children and mentally ill well controlled with treatment, respectively. No doctor was knowledgeable on obtaining consent from mentally incapacitated patients.

$61.9 \%$ and $66.66 \%$ had answered correctly for obtaining consent in emergencies from competent and incompetent patients respectively. No doctor reached the required standards of $100 \%$ knowledge on capacity to consent.

\section{Conclusion}

The audit revealed incomplete documentation and gaps in knowledge on obtaining consent. The need to conduct refresher programs and to introduce formal consent forms is highlighted.

Keywords: consent; awareness; documentation

\section{Introduction}

Every medical practitioner has an ethical, legal and professional responsibility to provide information and obtain informed consent prior to any invasive procedure on their patients. Consent is valid only if adequate information is supplied and the patient has the capacity to understand it and make a balanced decision, free from coercion ${ }^{1}$. Patients may withdraw consent at any time, thus one must allow sufficient time after delivery of information to arrive at a balanced decision. The ethical obligation to respect patients' autonomy sometimes conflicts with other issues such as beneficence and when children and mentally incapacitated are dealt with. The practicing doctor should have a very clear broad understanding on how to act in each situation to avoid litigation.

It is the common practice at NHSL and most other hospitals in Sri Lanka that the junior doctors in the team are involved in the process of obtaining consent. Contrary to this, the treating doctor is 
responsible for ensuring that the patient has consented for treatment ${ }^{1}$. Lack of understanding about the procedure and alternatives might lead to inadequate communication if junior doctors in the team are not provided with the exact information to be discussed.

Braddock et al evaluated audiotaped office visits of doctors and found that just $9 \%$ of decisions met their definitions of informed decision making, and fewer than $10 \%$ conducted a discussion about alternatives, risks and uncertainties ${ }^{2}$. A recent survey of medical professionals in Singapore showed that $17.3 \%$ did not disclose risks completely, $16.1 \%$ did not explain the benefits, and $17 \%$ did not discuss alternatives ${ }^{3}$. The literature review did not reveal any local studies on knowledge of informed consent. We therefore investigated the perception and practices among IMOs - the commonest cohort who obtain informed consent from patients.

\section{Methodology}

All IMOs of NHSL who were within the first 6 months of their internship were given a selfadministered questionnaire designed in two parts.

1. To recall a recently obtained informed consent and evaluate the practical application of existing knowledge and attitude towards informed consent.

2. To assess awareness on capacity to consent in commonly encountered special situations.

a) Competent patient

b) Child $<18$ years

c) Incompetent adult

d) Psychiatric patient, well controlled with treatment

e) Competent patient in an emergency

f) Incompetent patient in an emergency

The participants were approached individually and requested to complete the questionnaires at their leisure to minimize disturbance to ward work and to extract the maximum knowledge. Anonymity was maintained to avoid ethical conflicts. Out of the 48 IMOs, 42 responded. Study was conducted over one month. Data was analyzed statistically using SPSS 20.

\section{Results}

Demographics

17 respondents were male and 25 were female. 20 were interns in a surgical unit, 21 in general medicine and 2 in gynaecology. 39 had obtained consent from competent patients while there were 39 elective procedures.

\section{Table 1}

Method of delivering information to patient

\begin{tabular}{|l|c|}
\hline Method & $\begin{array}{c}\text { Number } \\
\text { (Total 42) }\end{array}$ \\
\hline Verbal & 20 \\
\hline Written & 10 \\
\hline Verbal+written & 8 \\
\hline Verbal+illustrations & 1 \\
\hline Verbal+written+illustrations & 3 \\
\hline
\end{tabular}

Table 2

Content of the information explained and documented

\begin{tabular}{|l|c|c|}
\hline Content & $\begin{array}{l}\text { Explained ( } \\
\text { Total 42) }\end{array}$ & Documented(Total 38) \\
\hline $\begin{array}{l}\text { Nature of } \\
\text { procedure }\end{array}$ & 42 & 37 \\
\hline Risks & 41 & 25 \\
\hline Alternatives & 18 & 7 \\
\hline $\begin{array}{l}\text { Risks and } \\
\text { benefits of } \\
\text { alternatives }\end{array}$ & 9 & 6 \\
\hline $\begin{array}{l}\text { Consequences if } \\
\text { untreated }\end{array}$ & 33 & 12 \\
\hline $\begin{array}{l}\text { All information } \\
\text { required }\end{array}$ & 9 & 3 \\
\hline
\end{tabular}

Only 5 had used a pre-prepared consent form for documentation. 38 had documented the consent, but documentation of all aspects was done by only $3(7.14 \%)$.

There was a statistically significant tendency of not documenting alternatives $(\mathrm{p}<0.01)$, risk versus benefit $(\mathrm{p}<0.01)$ and consequences if left untreated $(\mathrm{p}=0.032)$ despite providing information on them, when analyzed with chi square test.

$51.51 \%$ of doctors who had not given all details said they had inadequate time, $15.15 \%$ thought it was not important and other reasons were given by $33.33 \%$.

$73.80 \%$ obtained consent for elective procedures a day prior to the scheduled date. Only $15.38 \%$ had 
obtained consent before admission. 5.12\% had obtained consent 1 hour prior.

\section{Table 3}

Reasons for incomplete information delivery and documentation

\begin{tabular}{|l|l|l|}
\hline \multirow{2}{*}{$\begin{array}{l}\text { Reason as stated by medical } \\
\text { officers }\end{array}$} & Percentage \\
\cline { 2 - 3 } & Explanation & $\begin{array}{l}\text { Documenta } \\
\text { tion }\end{array}$ \\
\hline Inadequate time & $51.51 \%$ & $23.07 \%$ \\
\hline Did not think it is important & $15.15 \%$ & $10.25 \%$ \\
\hline $\begin{array}{l}\text { Other reasons (thought it is } \\
\text { unnecessary, duty of seniors, } \\
\text { unawareness of details, } \\
\text { paternalism) }\end{array}$ & $33.33 \%$ & $7.69 \%$ \\
\hline
\end{tabular}

\section{Table 4}

Responses on capacity to consent

\begin{tabular}{|c|c|c|c|c|c|c|}
\hline \multirow[t]{2}{*}{ Situation } & \multicolumn{6}{|c|}{ From whom to obtain consent } \\
\hline & $\begin{array}{l}\text { Patient } \\
\text { (1) }\end{array}$ & $\begin{array}{l}\text { Parent } \\
\text { (2) }\end{array}$ & $\begin{array}{l}\text { Next of } \\
\text { kin(3) }\end{array}$ & $\begin{array}{l}\text { Best } \\
\text { interest } \\
\text { of } \\
\text { patient } \\
\text { (4) }\end{array}$ & $\begin{array}{l}\text { Mult } \\
\text { resp } \\
\text { es }\end{array}$ & \\
\hline $\begin{array}{l}\text { Competent } \\
\text { adult }\end{array}$ & 40 & 0 & 0 & 0 & $1+4$ & 2 \\
\hline \multirow[t]{3}{*}{$\begin{array}{l}\text { Child }<18 \\
\text { years }\end{array}$} & \multirow[t]{3}{*}{0} & \multirow[t]{3}{*}{36} & \multirow[t]{3}{*}{0} & \multirow[t]{3}{*}{0} & $1+2$ & 2 \\
\hline & & & & & $2+3$ & 2 \\
\hline & & & & & $2+4$ & 2 \\
\hline \multirow[t]{3}{*}{$\begin{array}{l}\text { Incompetent } \\
\text { adult }\end{array}$} & \multirow[t]{3}{*}{0} & \multirow[t]{3}{*}{3} & \multirow[t]{3}{*}{31} & \multirow[t]{3}{*}{0} & $1+2$ & 1 \\
\hline & & & & & $1+3$ & 4 \\
\hline & & & & & $2+4$ & 2 \\
\hline \multirow{3}{*}{$\begin{array}{l}\text { Psychiatric } \\
\text { disease, } \\
\text { well } \\
\text { controlled } \\
\text { with } \\
\text { treatment }\end{array}$} & \multirow[t]{3}{*}{20} & \multirow[t]{3}{*}{2} & \multirow[t]{3}{*}{11} & \multirow[t]{3}{*}{1} & $1+2$ & 1 \\
\hline & & & & & $1+3$ & 1 \\
\hline & & & & & $1+4$ & 1 \\
\hline \multirow[t]{2}{*}{$\begin{array}{l}\text { Competent } \\
\text { patient in } \\
\text { emergency }\end{array}$} & \multirow[t]{2}{*}{26} & \multirow[t]{2}{*}{0} & \multirow[t]{2}{*}{0} & \multirow[t]{2}{*}{10} & $1+3$ & 1 \\
\hline & & & & & $1+4$ & 1 \\
\hline \multirow[t]{2}{*}{$\begin{array}{l}\text { Incompetent } \\
\text { patient in } \\
\text { emergency }\end{array}$} & \multirow[t]{2}{*}{0} & \multirow[t]{2}{*}{0} & \multirow[t]{2}{*}{4} & \multirow[t]{2}{*}{28} & $1+2$ & 1 \\
\hline & & & & & $3+4$ & 1 \\
\hline
\end{tabular}

Figure 1

Percentage correctly answered for different situations

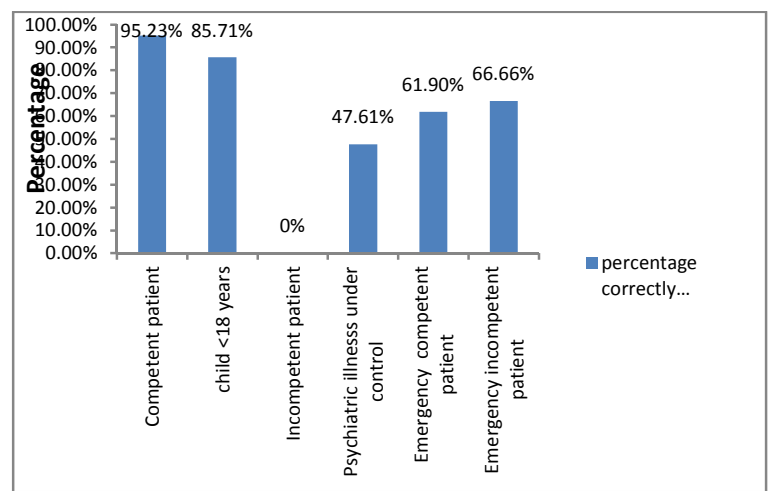

Table 5

Awareness on possibilities of obtaining consent in different situations

\begin{tabular}{|c|c|}
\hline $\begin{array}{c}\text { Number of correct answers given by } \\
\text { an individual }\end{array}$ & Number of participants \\
\hline 6 & 0 \\
\hline 5 & 6 \\
\hline 4 & 23 \\
\hline 3 & 6 \\
\hline 2 & 5 \\
\hline 1 & 0 \\
\hline 0 & 2 \\
\hline Total & 42 \\
\hline
\end{tabular}

\section{Discussion}

In accordance with the recommendations by various professional bodies, doctors have a duty to provide patients with sufficient information ensuring that the patient has the capacity to make an informed decision. The GMC guidelines define consent as patients and doctors making decisions together ${ }^{4}$. This highlights the equal responsibility both parties perceive when arriving at a decision. In addition to respecting human life and quality of professional care, emerging issues of litigation also makes clear documentation pivotal.

Only 23 out of 43 had given written/illustrated information. If such written information on commonly performed procedures is available, it will be more informative to patients, more convenient to doctors, and allow more time for clarification of doubts. A patient friendly leaflet 
containing written and illustrated information is the best possible way to enlighten patients about procedures.

A satisfactory number had informed the nature and the risks. A reasonable number had informed the consequences if left untreated and given opportunity to clarify doubts. However, information on alternatives and weighing the risk versus benefit was not satisfactory.

Majority had given inadequate time as the reason for incomplete information. This may be because they are taxed beyond their capabilities with the increasing workload despite the awareness. As reflected in the results, obtaining consent requires time and patience which is lacking in busy wards and clinics. Some thought that going in to all details is unnecessary which reflects a deficiency in either knowledge or attitude. One participant had stated that he did not discuss alternatives as seniors had decided on the particular surgery. As the treating doctor is ultimately responsible for ensuring that the patient has consented, proper guidance of juniors on relevant information to be discussed will make matters less complicated. This suggestion is supported by another doctor stating that he did not want to discuss alternatives as he was not aware of them. One doctor had stated that he usually does not go beyond explaining the nature unless specifically inquired. Another had not informed risks as he thought that the particular intervention is necessary for the health of the patient. These reflect the paternalism and concern on beneficence. Such gaps could have been avoided if proper insight on medical ethics was built in.

Majority had obtained consent for elective procedures a day prior to the scheduled date while 2 had done so one hour prior. Patient should be allowed sufficient time to arrive at a reasonable decision and 1 hour prior is not an acceptable time to provide new information. Only 6 out of 43 had obtained consent for elective procedures prior to admission which is the most acceptable time. However, busy clinics where patients are decided for surgery/ invasive procedures might not be a friendly environment to conduct such interactive sessions. Active decisions from administrative levels on efficient management of available resources are needed. Dedicating a separate doctor to educate on the procedures to the group scheduled by that clinic as a whole and then clarifying their doubts individually might be a time saving and more informative alternative.

4 had not documented consent at all. With the emerging issues on medical ethics, documentation is vital to safeguard oneself and the profession. At the end of explanation one should document the key elements noting what risks, benefits and alternatives were discussed. ${ }^{1}$ Even out of the 38 who had documented, only 3 had documented all details. Though majority had documented nature $(97.36 \%)$ and risks (65.78\%), there was a statistically significant tendency of not documenting alternatives $(\mathrm{p}<0.01)$, risk versus benefit $(\mathrm{p}<0.01)$ and consequences if left untreated ( $\mathrm{p}-0.032)$ despite providing information on them.

The importance of documentation to safeguard from later disputes needs to be emphasized repeatedly during refresher programs on consenting issues.

Only 5 had used a pre prepared consent form for documentation. Presence of such format helps to manage time effectively and make documentation more complete. This is reflected from the audit as those who used a pre prepared consent form had included most of the aspects required. Thus use of pre prepared consent forms for commonly practiced procedures is highly encouraged.

The second part of the questionnaire was designed to assess the theoretical knowledge on capacity to consent in commonly encountered situations.

Almost all (95.23\%) had correctly answered that a competent patient has to consent for himself and nobody else. However, 2 had thought it can also be done according to the best interest. This again is a reflection of prevailing paternalism.

$85.71 \%$ had correctly stated that parents have to consent on behalf of children less than 18 years. 2 each had thought child or next of kin can also consent or procedures can be done to the best interest in addition to parent consenting. Children under 18 years are presumed to be incompetent to consent for treatment by the common law of Sri Lanka. Parent, temporary carer or an authority 
with parental responsibility should consent unless the doctor decides that child has sufficient intelligence to appreciate fully what is proposed (Gillick competence) $^{1}$.

It was alarming that no doctor was capable of answering how to deal with incompetent patients. Majority (73.8\%) thought next of kin should consent. Though undoubtedly a good practice to discuss with relatives, no one can consent on medical treatment of an incompetent adult. Treatment should be done according to best interest of patient. If the attending doctor is not aware on this, treatment can be delayed unnecessarily specially when dealing with critically ill who might lack competence temporarily.

Only $47.61 \%$ had correctly responded that patients with psychiatric illness well controlled with treatment can consent for himself. If doctors seek other parties for consenting, it will be damaging to the self-esteem of patient.

$61.9 \%$ stated correctly that emergency procedures have to be performed with consent from competent patients. $23.8 \%$ had thought procedures can be performed according to the best interest of patient. Though these doctors might do their maximum for the benefit of patients, they will face problems in a court of law.

$66.66 \%$ had correctly stated that emergency procedures for incompetent patients can be performed according to best interest of patient. 8 had stated that next of kin can also consent. They will face a dilemma when there are contradictory views between next of kin and doctor which might again lead to unnecessary delays.

Unfortunately, no doctor reached the required standards of $100 \%$ awareness on capacity to consent. Majority (54.76\%) got 4 responses correct. 2 did not get any correct. This highlights the importance of proper education of practicing doctors on issues regarding consent.

\section{Conclusion}

Results highlighted gaps in both knowledge and attitude on obtaining informed consent among IMOs. Importance of documentation seems to be underestimated and introduction of a formal consent form for specific procedures is recommended. Organization of refresher programs and workshops on medical ethics is needed.

\section{References}

1. Bogod DG, Chambers WA, Gemill L et al. Consent for Anaesthesia: The Association of Anaesthetists of Great Britain and Ireland 2006. PMid:17090230

2. Braddock $\mathrm{CH}$, Edwards KA, Hasenberg NM et al. Informed decision making in outpatient practice: time to get back to basics. JAMA 1999; 282:231320. http://dx.doi.org/10.1001/jama.282.24.2313 PMid:10612318

3. Giam YC, Tay CSK, Goh CL, et al. Understanding the basic elements of informed consent: a survey of medical professionals. Annals Academy of Medicine Singapore. 2004; 33 : S93.

4. Consent: patients and doctors making decisions together. General Medical Council 2008. 